\title{
The Granulocyte-colony stimulating factor has a dual role in neuronal and vascular plasticity
}

\author{
Stephanie Wallner ${ }^{1 *}$, Sebastian Peters ${ }^{2}$, Claudia Pitzer ${ }^{3}$, Herbert Resch ${ }^{1,4}$, \\ Ulrich Bogdahn ${ }^{2}$ and Armin Schneider ${ }^{5}$
}

${ }^{1}$ Department of Traumatology and Sports Injuries, Spinal Cord Injury and Tissue Regeneration Center Salzburg, Paracelsus Medical University Salzburg, Salzburg, Austria, ${ }^{2}$ Department of Neurology, University Hospital Regensburg, Regensburg, Germany, ${ }^{3}$ Interdisciplinary Neurobehavioral Core, Ruprecht-Karls-University, Heidelberg, Germany, ${ }^{4}$ University Clinic of Traumatology and Sports Injuries Salzburg, Paracelsus Medical University Salzburg, Salzburg, Austria, ${ }^{5}$ SYGNIS Bioscience GmbH, Heidelberg, Germany

OPEN ACCESS

Edited by:

Thimios Mitsiadis,

University of Zurich, Switzerland

Reviewed by:

François Berthod,

Université Laval, Canada

Claudio Cantù,

University of Zurich, Switzerland

*Correspondence:

Stephanie Wallner

Department of Traumatology and Sports Injuries, Spinal Cord Injury and Tissue Regeneration Center Salzburg,

Paracelsus Medical University

Salzburg, Strubergasse 22,

5020 Salzburg, Austria

stephanie.wallner@pmu.ac.at

Specialty section

This article was submitted to

Stem Cell Research,

a section of the journal

Frontiers in Cell and Developmental

Biology

Received: 31 May 2015

Accepted: 23 July 2015

Published: 07 August 2015

Citation:

Wallner S, Peters S, Pitzer $C$, Resch $H$, Bogdahn $U$ and Schneider $A$ (2015) The Granulocyte-colony stimulating factor has a dual role in neuronal and vascular plasticity.

Front. Cell Dev. Biol. 3:48 doi: 10.3389/fcell.2015.00048
Granulocyte-colony stimulating factor (G-CSF) is a growth factor that has originally been identified several decades ago as a hematopoietic factor required mainly for the generation of neutrophilic granulocytes, and is in clinical use for that. More recently, it has been discovered that G-CSF also plays a role in the brain as a growth factor for neurons and neural stem cells, and as a factor involved in the plasticity of the vasculature. We review and discuss these dual properties in view of the neuroregenerative potential of this growth factor.

Keywords: SCI, ALS, G-CSF, neurogenesis, arteriogenesis, angiogenesis, neuroregeneration, plasticity

\section{Introduction}

In the last two decades the neuroscience community experienced a change of thought on the regeneration capacity of the central nervous system (CNS). The earlier dogma of incapability of CNS regeneration was overthrown by findings of astounding plasticity derived from neuronor neuronal network- inherent adaptations, fostered by neurogenesis and by supporting vasculogenesis. These findings have raised hopes for developing new treatment approaches for neurological diseases.

Granulocyte-colony stimulating factor (G-CSF) is a 19.6-kDa glycoprotein which has been wellcharacterized as a growth factor for hematopoietic progenitor cells. It is an FDA- and EMAapproved drug commonly used to treat neutropenia and to mobilize bone marrow hematopoietic stem cells for transplantation (Nicola et al., 1983). For many years G-CSF has been thought of as a highly specific growth factor in the hematopoietic system. However, more recent studies have shown the presence of the G-CSF/G-CSF-receptor (G-CSFR) system in the brain and roles in neuroprotection, neural tissue repair as well as improvement in functional recovery

Abbreviations: ALS, amyotrophic lateral sclerosis; ANG, angiogenin; ANGPT2, angiopoietin 2; BrdU, bromodeoxyuridine; CNS, central nervous system; EMA, european medicines agency; FDA, food, and drug administration; G-CSF, GranulocyteColony Stimulating Factor; G-CSFR, Granulocyte-Colony Stimulating Factor Receptor; GM-CSF, Granulocyte-macrophage colony stimulating factor; HUVEC, human umbilical vein endothelial cells; IL, interleukin; kDa, kilo Dalton; MAP-2, microtuble-associated protein 2; NeuN, neuronal nuclei; NSC, neuronal stem cell; PCA, posterior communicating artery; SCI, Spinal Cord Injury; SOD1, superoxide dismutase 1; SVZ, subventricular zone; TNF, tumor necrosis factor; VEGF, vascular endothelial growth factor; 3-VO, 3-vessel occlusion. 
have been described (Schneider et al., 2005b). The elevated expression of G-CSF/G-CSFR on neurons subjected to ischemia suggested that G-CSF serves as an autocrine protective signaling mechanism in response to neural injury. Furthermore, G-CSF receptors may also be present on glial cells, however at much lower levels (Schneider et al., 2005a). G-CSF exerts potent antiapoptotic activity in neurons that appears largely responsible for its neuroprotective effects in acute injury models. In addition, GCSF stimulates neurogenesis (Schneider et al., 2005b; Schmidt et al., 2015), arteriogenesis in the CNS (Sugiyama et al., 2011), and markedly improves long-term behavioral outcome after cortical ischemia (Schneider et al., 2005a) or spinal cord injury (SCI) (Dittgen et al., 2012). There is debate on the role of GCSF-stimulated hematopoietic stem cells that may migrate to the injured CNS. Due to those effects and the ability of G-CSF to cross the intact blood brain barrier (Schneider et al., 2005b), facilitating peripheral administration, G-CSF got in the focus for treating acute and chronic neurodegenerative disorders, with protective and recovery enhancing effects in animal models of stroke, amyotrophic lateral sclerosis (ALS), Alzheimer's disease, Parkinson's disease, traumatic brain injury, and SCI (Diederich et al., 2012). In this review, we concentrate on direct and indirect effects of the cytokine G-CSF on CNS spinal regeneration especially by neurogenic and vasculogenic mechanisms and critically discuss the available pre-clinical and clinical evidence in SCI and ALS.

\section{G-CSF-mediated Neural Progenitor Activation}

The concept of adult neurogenesis is a relatively new one and has added one principally new option to influence plasticity and regeneration in the CNS. Neurogenesis can occur in the hippocampus (dentate gyrus), the olfactory bulb, and the subventricular zone (SVZ) (Winner and Winkler, 2015). There is debate whether adult neurogenesis occurs in the spinal cord near the central canal. One physiological role for hippocampal neurogenesis is pattern separation. There has been debate on whether neurogenesis is even relevant for humans, but detailed post-mortem studies on humans using radiocarbon dating in the brain have revealed that neurogenesis is particularly strong in the human hippocampus. Pathophysiologically, neurogenesis has been invoked as a possible causative or modifying factor in depression and schizophrenia. The case is stronger for depression, since several antidepressants stimulate neurogenesis (Hanson et al., 2011). Further, physical exercise which is anti-depressant, stimulates neurogenesis in rodents (van Praag et al., 1999; Yau et al., 2011) as well as humans (Déry et al., 2013). Interestingly, antidepressant medication for example fluoxetine, typically requires several weeks in order to be therapeutically active, which corresponds with the duration of newly generated nerves to be functional integrated. Moreover, impairment of neurogenesis has been shown to block the antidepressive activity of antidepressants such as fluoxetine (Santarelli et al., 2003). Also, imaging studies have shown a decrease in hippocampal volume in some cases.
A function for G-CSF in stimulating neurogenesis was first described in 2005 in mice, treated subcutaneously with G-CSF (Schneider et al., 2005a). Neurogenesis was quantified using a standard bromodeoxyuridine (BrdU) incorporation protocol. While healthy mice showed a doubling of BrdU/neuronal nuclei (NeuN) double positive cells in the hippocampus 6 weeks after treatment initiation, mice subjected to cortical ischemia further increased that rate, pointing to a particular relevance of this stimulation also under pathological conditions to potentially enhance CNS plasticity. Most likely, stimulation of progenitor cells occurs via the G-CSF receptor present on these cells. Interestingly, the G-CSFR is already expressed at the embryonic stage in radial glia, which also later form the adult neural precursor cells (Kirsch et al., 2008). In G-CSF knock-out mice, hippocampal neurogenesis is strongly diminished, and the mice show deficits in behavioral plasticity (Diederich et al., 2009). For SCI and ALS the question whether neurogenesis occurs in the spinal cord and could be enhanced by G-CSF is of particular importance as this is the site of the main pathology. A careful review of the data on progenitor cells in the spinal cord comes to the conclusion that these cells exist in the ependymal zone of the central canal, but are restricted to a gliogenic fate (Sabelström et al., 2014). However, this restriction can be overcome by transplanting those cells into the hippocampus (Shihabuddin et al., 2000) and possibly growth factors like G-CSF could help to overcome this restriction in the spinal cord, but experimental proof for this is lacking so far.

\section{G-CSF-mediated Vasculogenic Effects}

Prior to discussing effects on the vasculature it is important to clarify some conceptual issues. Overall, arteriogenesis refers to the remodeling of pre-existing capillary connections into conducting vessels by mechanisms involving shear stress and monocyte recruitment (Van Royen et al., 2001). Angiogenesis, on the other hand, describes the process of capillary sprouting driven by hypoxia and vascular endothelial growth factor (VEGF) (Heil et al., 2006). While angiogenesis is a key mechanism supporting tumor growth by improving local oxygen diffusion distances, it does not contribute to substantial increases in blood conductance, since only end-stage capillaries in the circulation are created (Buschmann and Schaper, 1999, 2000). Arteriogenesis is therefore a mechanism that is relevant for ischemic conditions such as vessel occlusions and decreased blood flow. The first hematopoietic factor for which evidence was found for a role in arteriogenesis was not G-CSF, but Granulocyte-macrophage colony stimulating factor (GM-CSF), as early as 2001 by Buschmann et al. (2001). GM-CSF was selected based on its propensity to stimulate monocyte and thrombocyte generation and the hypothesis of a key role of monocytes and thrombocytes in the arteriogenic process and stem cell niche. While these experiments made use of the femoral occlusion model in rabbits to observe arteriogenesis from pre-existing anastomosing capillaries, a publication from 2003 demonstrated also induction of arteriogenesis in the CNS (Buschmann et al., 2003). In this work, the authors made 
use of the 3-vessel occlusion (3-VO) model. In this model, both vertebral arteries and the left carotid artery are occluded. Treatment of rats over 7 or 21 days with $40 \mu \mathrm{g} / \mathrm{kg} /$ day GMCSF led to a significantly larger increase in the diameter of the left PCA (posterior communicating artery) (72 vs. 39\% increase in control animals after 7 days of treatment). Moreover, GMCSF treatment also preserved good $\mathrm{CO}_{2}$-reactivity, indicating that the vessel was functionally intact with regard to blood flow regulation. Moreover, this treatment also resulted in an improved energy situation (ATP-depletion) in the hypoperfused brain in this 3-VO model (Schneeloch et al., 2004). In 2006, Deindl and colleagues were the first who also detect arteriogenic effects of GCSF in a myocardial infarction model in mice. Treatment with $100 \mu \mathrm{g} / \mathrm{kg} /$ day G-CSF for 5 consecutive days after myocardial infarction led after 30 days observation to decreased mortality ( 68.8 vs. $46.2 \%)$, reduced final infarct size, and reduced thinning of the left ventricular wall. Moreover, hemodynamic parameters were improved such as ejection fraction, contractility, and relaxation of the ventricle. The authors could show G-CSF induced arteriogenesis from collateral vessels with proliferation of endothelial cells and smooth muscle cells (Deindl et al., 2006). Also, a decreased potential for arrhythmia generation in the infarcted heart was noted (Kuhlmann et al., 2006). A number of smaller clinical trials have indeed been conducted in patients with myocardial infarction with mixed results, the latest by Hibbert and colleagues in 86 patients (Hibbert et al., 2014). Later, arteriogenic effects of G-CSF were also noted in cerebral ischemia models (Sugiyama et al., 2011) and in the 3-VO model described above (Duelsner et al., 2012). GCSF showed a very similar profile to GM-CSF in the 3VO model in terms of doses used and treatment effects. In addition to the beneficial effects of arteriogenesis for blood flow enhancement, locally increased angiogenesis in the CNS could provide the critical neurovascular niche for neurogenesis and neuronal remodeling. Indeed, a number of articles suggest angiogenic activity of G-CSF in the brain. Bussolino and colleagues were the first to describe angiogenesis evoked by G-CSF (Bussolino et al., 1991). They used G-CSF secreting pellets implanted into the cornea of rabbits and observed formation of new capillaries within 8 days after implantation. Boiled G-CSF did not achieve this effect. In vitro, G-CSF enhanced proliferation and migratory behavior of HUVEC cells. In the brain, Lee et al. reported much later that the vascular surface area, vascular branch points, vascular length, number of BrdU-labeled endothelial cells, and endothelial nitric oxide synthase and angiopoietin 2 (ANGPT2) expression were all significantly increased in G-CSF-treated rats in the focal cerebral ischemia model (Lee et al., 2005). Ohki and colleagues found that G-CSF increased plasma levels of VEGF from neutrophils in vivo (Ohki et al., 2005). Furthermore, blockade of the VEGF pathway eliminated G-CSF-induced angiogenesis in a hindlimb ischemia model (measured as capillary density in the gastrocnemius muscle), suggesting that G-CSF-induced vasculogenesis is VEGF-dependent and could be indirectly mediated by this mechanism (Ohki et al., 2005). The finally responsible mechanism for these vasculogenic effects of GCSF has not been unambiguously established. Direct effects on endothelial cells via the G-CSF receptor, increase in monocyte counts, and indirect effects via induction of VEGF release have all been discussed. In summary, G-CSF has both arteriogenic and angiogenic effects, thereby both enabling increased blood flow via generation of conductance vessels, and improving local oxygen diffusion and providing a neurovascular environment for repair mechanisms in the CNS.

\section{G-CSF in SCI}

Acute SCI is associated with a significant burden of illness. Worldwide the estimated range of the incidence of SCI lies between 15 and 30 per million inhabitants per year (Wyndaele and Wyndaele, 2006). Therapeutic approaches in the acute phase including early resuscitation, steroid application, decompression/stabilization, have been reported to be associated with somewhat better outcomes in incomplete SCI. Thus, far, there is still no really effective treatment for SCI available, and the degree of neurological recovery is largely dependent on the magnitude of the initial injury. A considerable number of animal studies using various models of SCI have demonstrated convincing beneficial effects of GCSF therapy (Table 1). Mechanisms triggered by G-CSF include anti-apoptotic effects and improved neurite outgrowth (Pitzer et al., 2010). Vasculogenesis certainly has a beneficial role for SCI repair and in limiting secondary damage after the initial traumatic event (Oudega, 2012). The degree of angiogenesis during the subacute phase after SCI correlates with regenerative responses, and the newly formed vascular bridge might provide scaffolding to accelerate axonal regeneration across the injury site. Angiogenesis might contribute to the regenerative response of neural tissue and enhance recovery of locomotor function after injury. Recent reports demonstrated the pro-regenerative effects of G-CSF in SCI which could be due to the enhancement of angiogenesis (Kawabe et al., 2011; Dela Peña et al., 2015). Kawabe and colleagues report significantly increased vessel numbers and increased expression of angiogenic cytokines after treatment with G-CSF in an experimental SCI model (Kawabe et al., 2011). GCSF significantly promoted angiogenesis in both the white and gray matter of the spinal cord after injury. The total number of vessels with a diameter $>20 \mu \mathrm{m}$ was significantly greater and expression of angiogenic cytokines was significantly higher than in the control group. The G-CSF-treated group showed greater recovery of hindlimb function than the control group. As for a contribution of neurogenesis to the beneficial effects of G-CSF treatment, the problem with restricted neurogenesis in the spinal cord applies here. However, for SCI there is a way around this restriction and this is by making use of stem cell transplantation. An example of this approach was provided by Pan et al. (2008). Neural stem cells (NSC) were embedded in fibrin glue in combination with or without G-CSF and were transplanted into the gap in the injured spinal cord. Higher expression levels of NeuN and MAP-2 and advanced regeneration according to the clinical motor score, motor evoked potential and conduction latency was observed in the group treated the fibrin glue, G-CSF and NSC compared to the group 
TABLE 1 | Published preclinical studies in the use of G-CSF for SCI.

\begin{tabular}{|c|c|c|c|c|}
\hline Drug/dosage & $\begin{array}{l}\text { Application/treatment } \\
\text { duration }\end{array}$ & Outcome & $\begin{array}{l}\mathrm{SCl} \\
\text { model/recipients }\end{array}$ & References \\
\hline $\begin{array}{l}\text { G-CSF } 200 \mu \mathrm{g} / \mathrm{kg} / \text { day } \\
\pm \text { BMDC ( } 4 \text { weeks } \\
\text { prior SCl) }\end{array}$ & $\begin{array}{l}\text { sc. injected immediately } \\
\text { after injury for } 5 \text { consecutive } \\
\text { days }\end{array}$ & $\begin{array}{l}\text { - Increased number of neutrophil antigen-negative } \\
\text { BMDC in the lesioned site } 24 \mathrm{~h} \text { after injury } \\
\text { - Increased number of BMDC } 6 \text { weeks after injury } \\
\text { - Most of the BMDC in the lesioned site were Mac-1+ } \\
\text { - Spared white matter was significantly larger } \\
\text { - Recovery of hindlimb function }\end{array}$ & $\begin{array}{l}\text { Compression model } \\
\text { at T8 level, C57BL/6 } \\
\text { mice }\end{array}$ & Koda et al., 2007 \\
\hline G-CSF $200 \mu \mathrm{g} / \mathrm{kg} /$ day & $\begin{array}{l}\text { sc. injected immediately } \\
\text { after injury for } 5 \text { consecutive } \\
\text { days }\end{array}$ & $\begin{array}{l}\text { - G-CSF Receptor expression by neurons in the spinal } \\
\text { cord } \\
\text { - Prevented glutamate-induced neuronal death during } \\
\text { the acute phase } \\
\text { - Increased number of surviving neurons after chronic } \\
\text { phase } \\
\text { - Increased recovery of hindlimb motor function }\end{array}$ & $\begin{array}{l}\text { Compression model } \\
\text { at T7-T8 level, } \\
\text { BALBc/Cr mice }\end{array}$ & Nishio et al., 2007 \\
\hline G-CSF $50 \mu \mathrm{g} / \mathrm{kg} /$ day & $\begin{array}{l}\text { sc. injection, within the first } \\
72 \mathrm{~h} \text { after injury for } 3 \\
\text { consecutive days }\end{array}$ & $\begin{array}{l}\text { - G-CSF Receptor expression on microglia cells } \\
\text { - Microglia recruitment to the injury site in the first } 72 \mathrm{~h} \\
\text { - Inhibited expression of pro-inflammatory factors } \\
\text { promoted the expression of neurotrophic factors } \\
\text { - Affect activation status of microglia } \\
\text { - Inhibited the expression of markers of M1 macrophage } \\
\text { in BV2 microglial cell line in vitro } \\
\text { - Promoted microglia to adopt M2 phenotype } \\
\text { - NFkB was involved in G-CSF induced M2 polarization } \\
\text { - IBA1+ cells within the lesion site after G-CSF treatment } \\
\text { - Attenuated accumulation of IBA1+ cells in the gray } \\
\text { and white matter } \\
\text { - Increased cell viability of BV2 microglial cell line } \\
\text { - Reduced expression of NFKB in BV2 microglial cell line }\end{array}$ & $\begin{array}{l}\text { Hemisection model at } \\
\text { level T9-T11, } \\
\text { Kunming mice }\end{array}$ & Guo et al., 2013 \\
\hline $\begin{array}{l}\text { G-CSF } 50 \mu \mathrm{g} / \mathrm{kg} / \mathrm{day} \pm \\
\text { BMC, MSC }\end{array}$ & $\begin{array}{l}\text { sc. injection on day } 7 \text { after } \\
\text { SCl for } 5 \text { consecutive days }\end{array}$ & $\begin{array}{l}\text { - Improved functional recovery (BBB score, plantar test) } \\
\text { - Improved behavioral parameters } \\
\text { - Increased cross sectional areas of the white matter }\end{array}$ & $\begin{array}{l}\text { Compression model } \\
\text { at T8-T9 level, Wistar } \\
\text { rats }\end{array}$ & Urdzíkova et al., 2006 \\
\hline $\begin{array}{l}\text { G-CSF } 300 \mu \mathrm{g} / \mathrm{kg} / \text { day } \\
\pm \text { SCF }\end{array}$ & $\begin{array}{l}\text { sc. injection on day } 11 \text { after } \\
\text { SCl for } 10 \text { consecutive days }\end{array}$ & $\begin{array}{l}\text { - Improved recovery of hindlimb motor function (BBB } \\
\text { score) } \\
\text { - Increased number of intrinsic BrdU+ cells } \\
\text { - Increased number of intrinsic F4/80+ cells } \\
\text { - Proliferation of OPC was activated } \\
\text { - Activation of intrinsic spinal cord cell proliferation } \\
\text { - Increase in intrinsic microglia cells was observed in } \\
\text { lesion } \\
\text { - No effects of SCF or G-CSF on the migration of } \\
\text { transplanted BMDC to the lesion sites }\end{array}$ & $\begin{array}{l}\text { Static contusion } \\
\text { model at level } \\
\text { T11-T12, C57BL/6 } \\
\text { mice }\end{array}$ & Osada et al., 2010 \\
\hline $\begin{array}{l}\text { G-CSF iv. } 60 \mu \mathrm{g} / \mathrm{kg} \text { sc. } \\
30 \mu \mathrm{g} / \mathrm{kg} / \text { day }\end{array}$ & $\begin{array}{l}\text { Single dose injected iv. } \\
\text { immediately after injury } \\
\text { ( } 5 \text { min after surgery) } \\
\text { followed by continuous sc. } \\
\text { application for } 2 \text { weeks }\end{array}$ & $\begin{array}{l}\text { - G-CSF Receptor is upregulated in the CNS upon SCI } \\
\text { - Counteracts apoptotic cell death in the injured spinal } \\
\text { cord } \\
\text { - Increased expression of the anti-apoptotic Bcl-XL gene } \\
\text { - Promotes neurite outgrowth in vitro }\end{array}$ & $\begin{array}{l}\text { Transection model at } \\
\text { level T8-T9 } \\
\text { (transected to 75\%), } \\
\text { C57BL/6 mice }\end{array}$ & Pitzer et al., 2010 \\
\hline
\end{tabular}


TABLE 1 | Continued

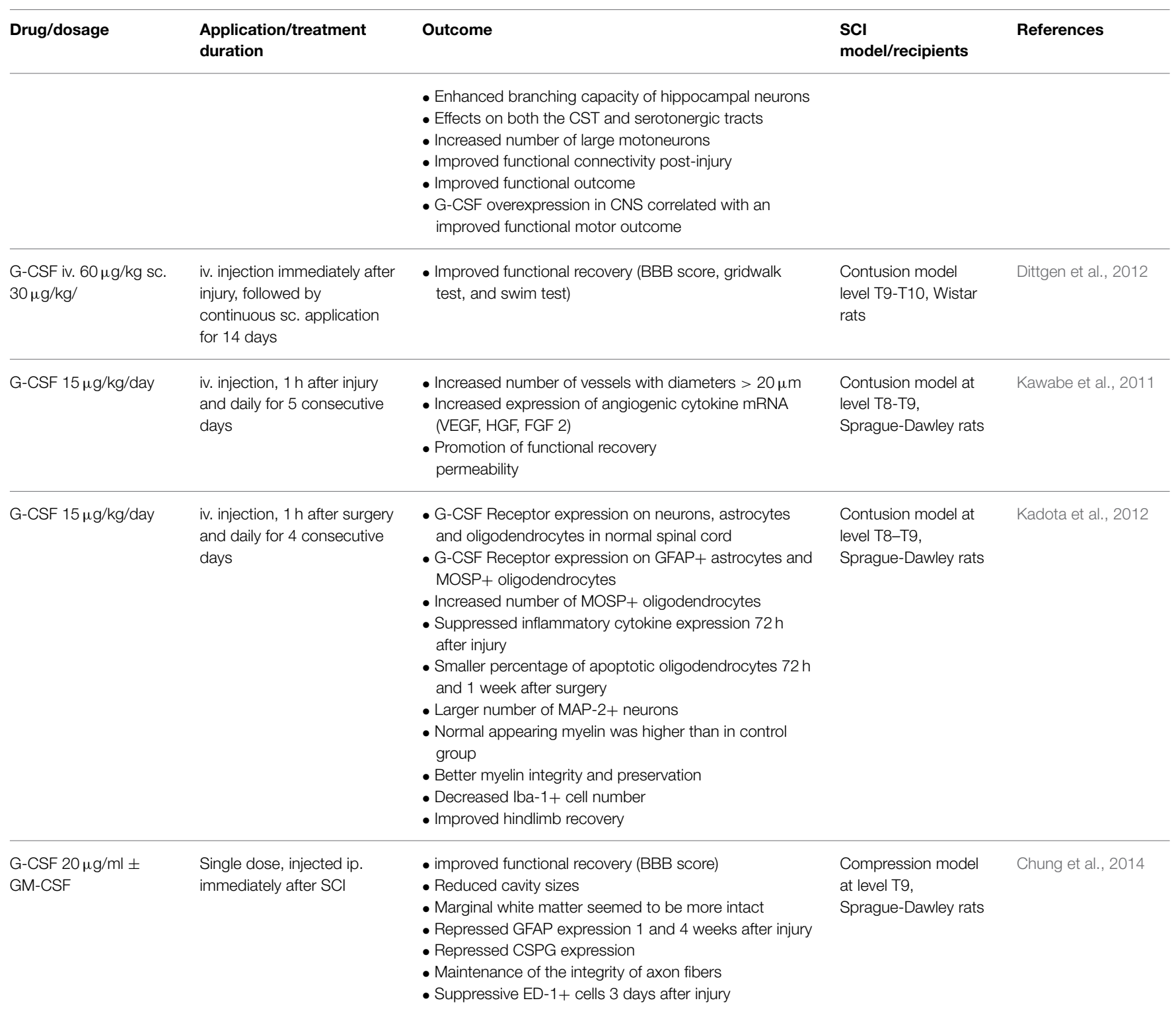

BBB, Basso, Beatti, and Bresnahan locomotor rating scale; BMC, bone marrow cells; BMDC, bone marrow derived cells; BV2, micro glia cell line; CNS, central nerve system; CSPG, chondroitin sulfate proteoglycan; MSC, mesenchymal stem cells; CST, corticospinal tract; FGF2, fibroblast growth factor 2; GFAP, Glial fibrillary acidic protein; GM-CSF, granulocytemacrophage colony stimulating factor; HGF, hepatocyte growth factor; IP, intraperitoneal; IV, intravenous; LPO, lipidperoxidation; M1, Macrophage type 1; M2, Macrophage type 2; MAP-2, microtubule associated protein; MDA, Malondialdehyde; MOSP, myelin oligodendrocyte-specific protein; MPO, Myeloperoxidase; MPSS, Methylprednisolone sodium succinate; NSC, neuronal stem cells; OPC, oligodendrocyte precursor cell; SC, subcutaneous; SCF, stem cell factor; SCI, spinal cord injury; VEGF, vascular endothelial growth factor.

without G-CSF (Pan et al., 2008). Based on the considerable preclinical evidence a number of smaller clinical trials have been initiated (Table 2). Several of these clinical studies demonstrated a neurological and functional improvement in SCI patients treated with G-CSF (Takahashi et al., 2012; Derakhshanrad et al., 2013; Inada et al., 2014; Saberi et al., 2014). Sakuma et al examined patients with a compression myelopathy and observed reduced progression of myelopathy in all 15 treated patients. Neurological improvements in motor and sensory functions were obtained in all patients after the administration, although the degree of improvement differed among the patients (Sakuma et al., 2012).

\section{G-CSF and ALS: Preclinical and Preliminary Clinical Research}

ALS represents a progressive and fatal neurodegenerative disease affecting motor neurons with a typical median disease course of 2-5 years and a lifetime risk of 1:400 (Ingre et al., 2015). A large number of clinical trials have been undertaken for this terrible disease, but the only approved drug so far is riluzole with limited treatment effects (Miller et al., 2012). Preclinical studies demonstrated that chronic or repeated subcutaneous administrations of G-CSF exert positive effects on survival rate, disease progression and immune status of SOD1-G93 mice 


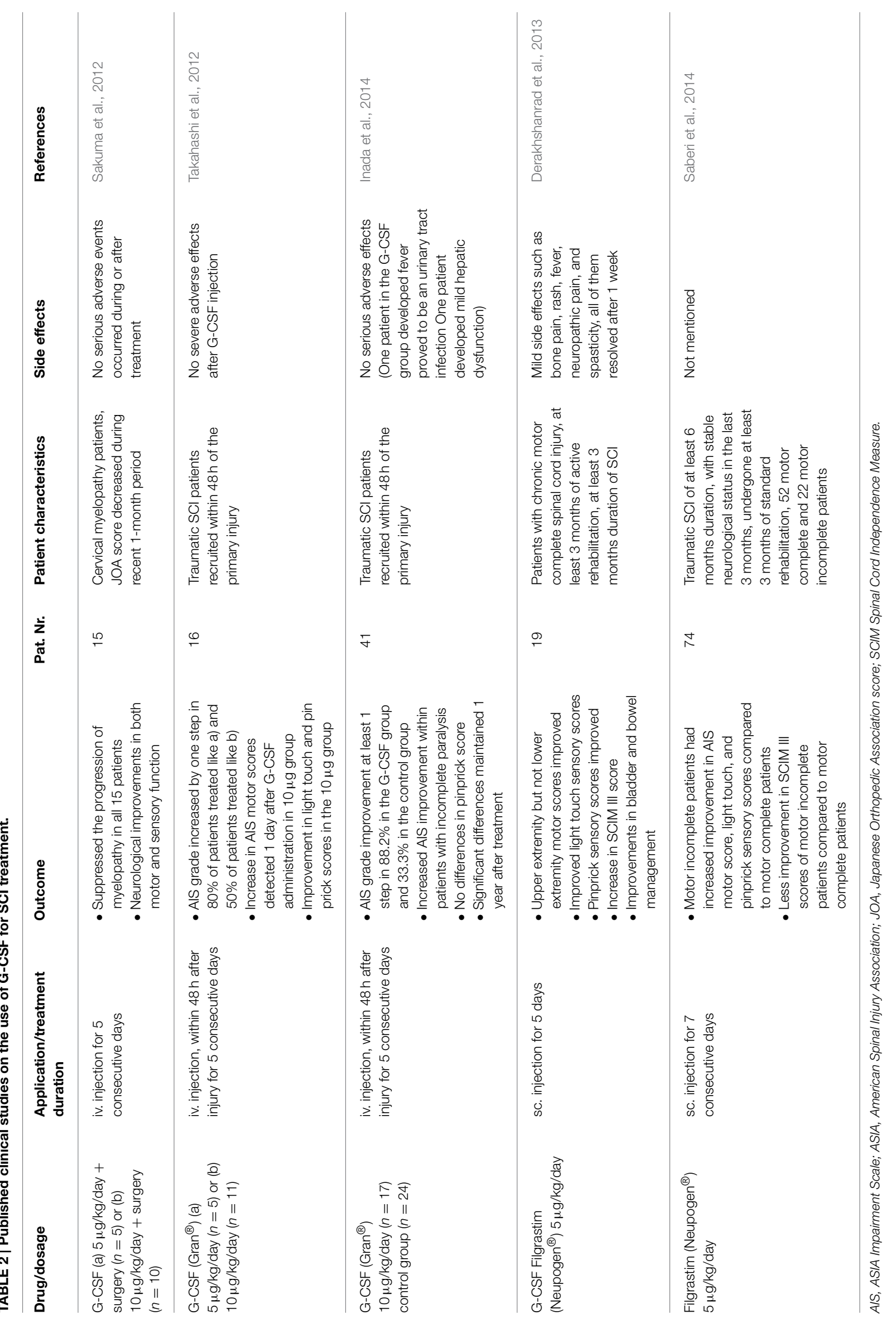


(for details see Table 3). Some reports describe more genderspecific effects in ALS mouse models with positive effects on survival rate and motor performance only present in male but not female mice (Naumenko et al., 2011). Mechanisms that have been described include suppression of neuronal apoptosis and oligodendrocyte cell death by regulating the expression of apoptosis related proteins (Nishio et al., 2007; Pitzer et al., 2008). Another claimed mechanism of action is via mobilizing bone marrow cells into the spinal cord (Koda et al., 2007), or enhancing the availability of circulating hematopoietic stem cells in neuronal lesion sites and their ability for neurogenesis and angiogenesis (Nishio et al., 2007), although this is a very debated field. Moreover, reducing demyelination and expression of inflammatory cytokines such as TNF- $\alpha$ and IL- $1 \beta$ could be contributing to improved outcome after G-CSF treatment (Koda et al., 2007; Nishio et al., 2007; Kawabe et al., 2011; Kadota et al., 2012).

Several angiogenic key players may be related to ALS with VEGF being the first described factor to contribute to ALS (Oosthuyse et al., 2001) and angiogenin (ANG) recently identified as a second angiogenic element related to that disease (Gao and $\mathrm{Xu}, 2008$ ). VEGF represents a pro-angiogenic factor with neuroprotective properties. In vitro as well as in vivo studies showed that VEGF promotes neuronal survival (Silverman et al., 1999; Jin et al., 2000a,b) and prolongs the life span of ALS animal models (Lambrechts et al., 2003; Storkebaum and Carmeliet, 2004; Storkebaum et al., 2004). Several clinical studies investigate the VEGF-system as a possible treatment option for patients suffering from ALS (Pronto-Laborinho et al., 2014). An enhanced angiogenesis might protect motoneurons from degradation by increasing neurovascular perfusion. Studies demonstrate a correlative reduction in the human umbilical vein endothelial cell proliferative and angiogenic activities, which may contribute to the induction of ALS (Crabtree et al., 2007; Wu et al., 2007). Therefore, G-CSF might act as potent medication for the treatment of ALS by activating pro-angiogenic systems.

With regard to neurogenesis as a possible mechanism there are no data available from animal models that demonstrate a direct regenerative effect of G-CSF treatment on the first or second motoneuron. However, hippocampal and SVZ neurogenesis are certainly triggered and enhanced under the chronic GCSF treatment protocols used in the animal studies that show beneficial effects of G-CSF treatment (Pitzer et al., 2008; Henriques et al., 2011) and one could speculate that this could indirectly functionally ameliorate the ALS phenotype via enhanced motor learning. There are papers that report enhanced progenitor cell proliferation and migration in the ependymal zone of the central canal in the lumbar spinal cord of ALS mouse models (Chi et al., 2006a,b, 2007), but true neurogenesis has not been reported in these studies. Based on these pre-clinical findings several smaller studies in ALS patients have been initiated with promising outcomes (Table 4) and no severe adverse effects even following longterm administration (Grassinger et al., 2014; Khomenko et al., 2015) Some studies reported no beneficial effects of G-CSF for patients suffering from ALS (Nefussy et al., 2010; Chiò et al., 2011).

\section{Conclusion and Clinical Implications}

In this review we have described the neuroregenerative potential of the hematopoietic growth factor G-CSF for SCI and ALS with a focus on vasculogenic and neurogenic mechanisms of action. Apart from all other arguments in favor of G-CSF as a novel type of neuroprotective drug, particularly due to its multiple mechanisms of action, and broad preclinical proof of principle one major advantage of this protein is that we are dealing with a drug with a well-known pharmacological profile, and an excellent safety record. Appropriate intervention in SCI depends on the nature, extent, and duration of the disease state, as pathophysiology can dramatically evolve over time. The initial mechanical damage occurs immediately after SCI followed by a cascade of potentially harmful secondary events that include the formation of free radicals, detrimental inflammatory responses and death of neurons and glia. A drug counteracting the induction of the secondary damage and promoting neuroregeneration is for major importance in the treatment of patients suffering from acute or chronic CNS diseases. Acute SCI causes immediate mechanical damage to the microvasculature of the cord followed by a secondary injury to the vessels, this combination produces spinal cord ischemia. Thus, angiogenesis is critically important to reduce secondary damage to the spinal cord vasculature. G-CSF plays a major function in the induction of angiogenesis and arteriogenesis which may promote neuroregeneration via the induction of a regeneration-friendly environment. How endogenous neurogenesis can contribute to SCI regeneration is unclear at present, spinal cord neurogenesis does not appear to play a significant role-central neurogenesis may however wellcontribute to recovery processes due to an increased level of plasticity for central "rewiring" of descending motor pathways. Local transplantation approaches together with G-CSF appear as an attractive way toward exploiting neurogenesis as a repair mechanism.

Clinical trials conducted so far look promising, and at least G-CSF treatment appears feasible and safe. However, proper controlled and randomized trials are lacking to draw sound conclusions. Many questions are on the table regarding the timing of treatment post-injury: (acute vs. delayed), G-CSF dosing (high dose, low dose), the treatment mode (chronic continuous vs. intermittent; intravenous vs. subcutaneous or even locally applied). For ALS, the antiapoptotic properties, protection of the neuromuscular junction, immune modulating, as well as angiogenic properties appear key in counteracting the pathology. As in SCI, a multitude of pathophysiological processes need to be addressed together, which is an argument for a growth factor as therapeutic agent (Henriques et al., 2010). The direct impact of the neurogenic potential of G-CSF for modifying the disease course is not so clear at the present state of knowledge. As is the situation with SCI, there are interesting clinical studies that indicate feasibility and safety of treatment, 
TABLE 3 | Published preclinical studies in the use of G-CSF for ALS.

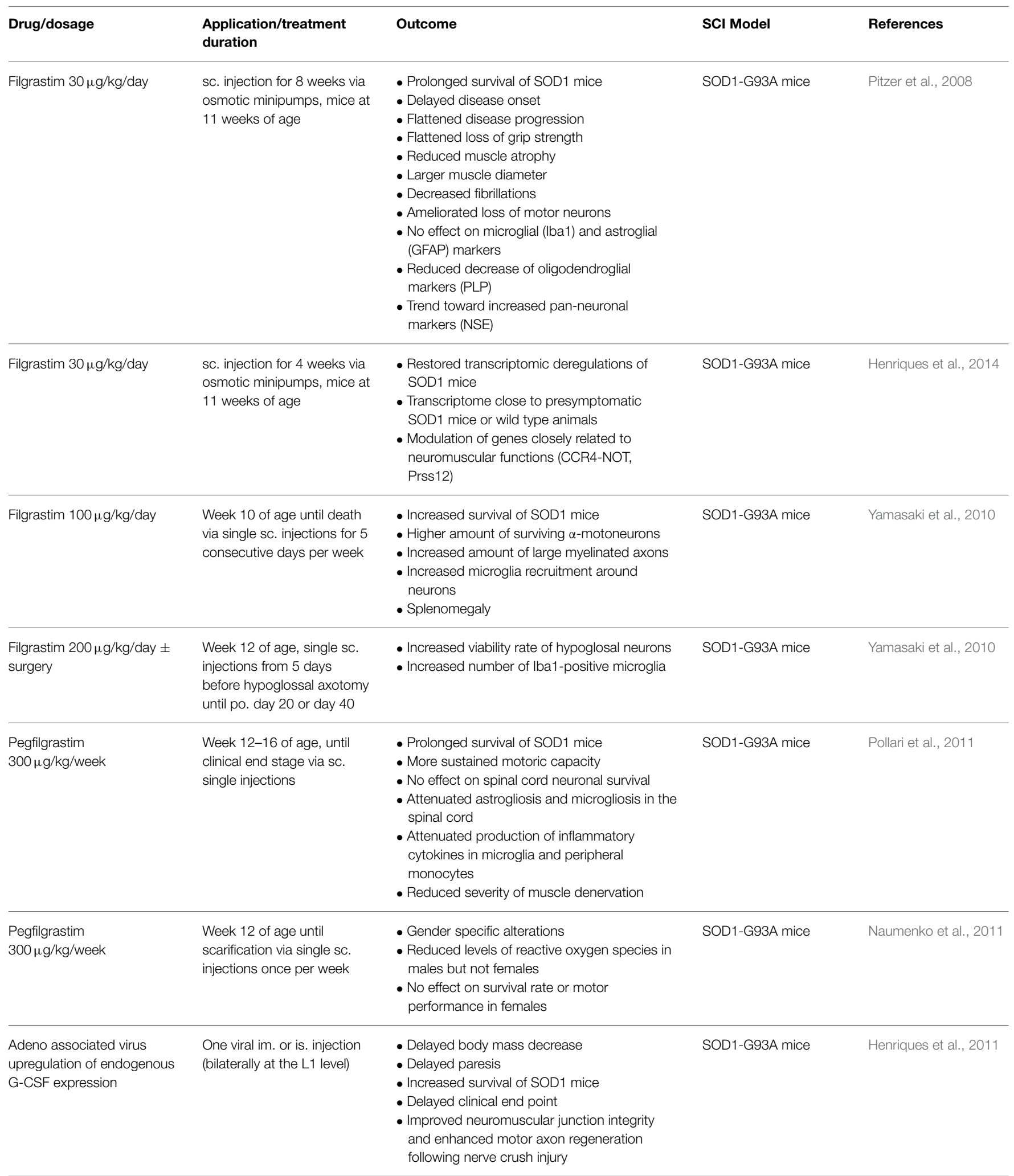

Iba1, ionized calcium-binding adapter molecule; IM, intramuscular; IS, intraspinal; GFAP, glial fibrillary acidic protein; NSE, neuron specific enolase; PLP, proteolipid protein; PO, post operation; SC, subcutaneous. 


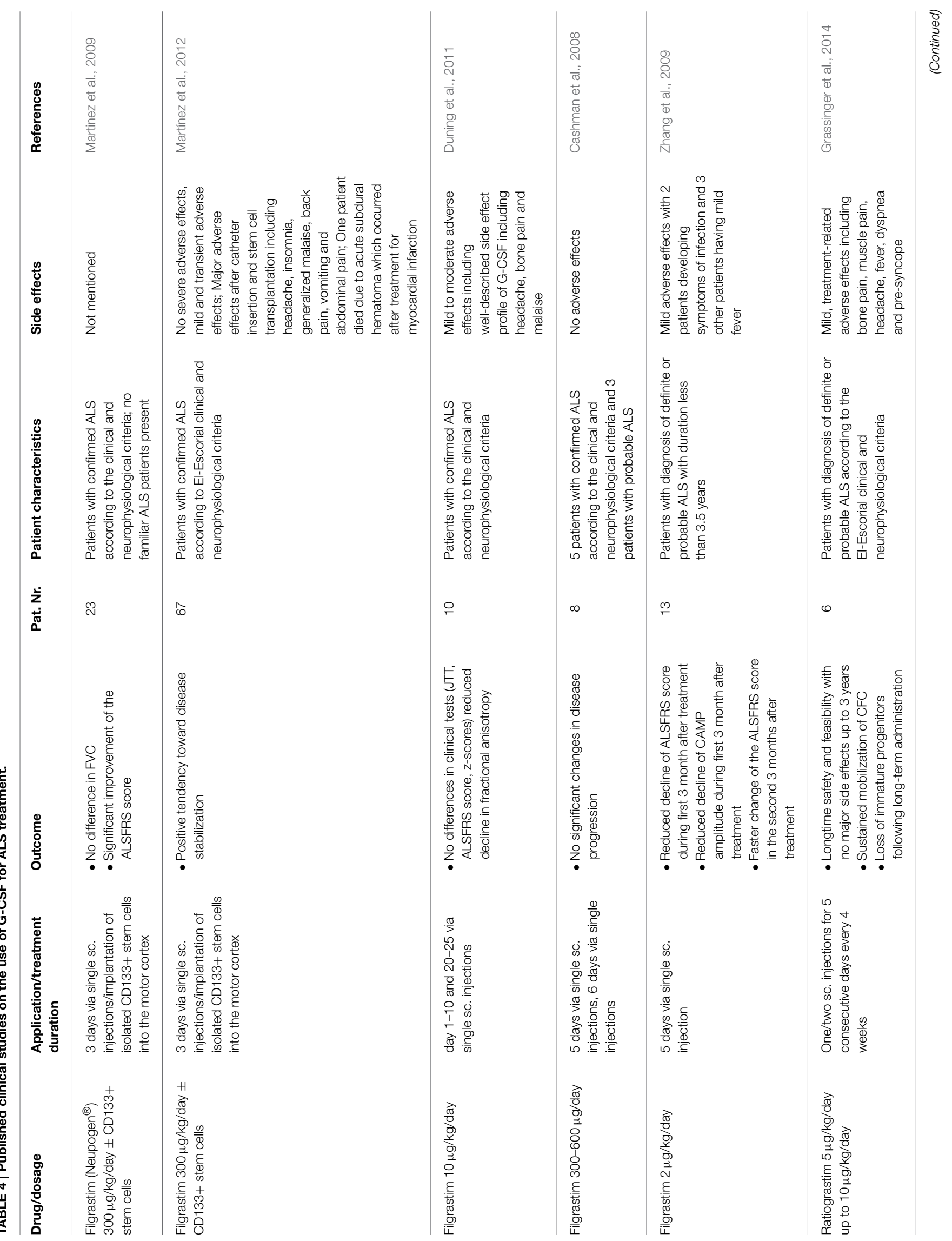




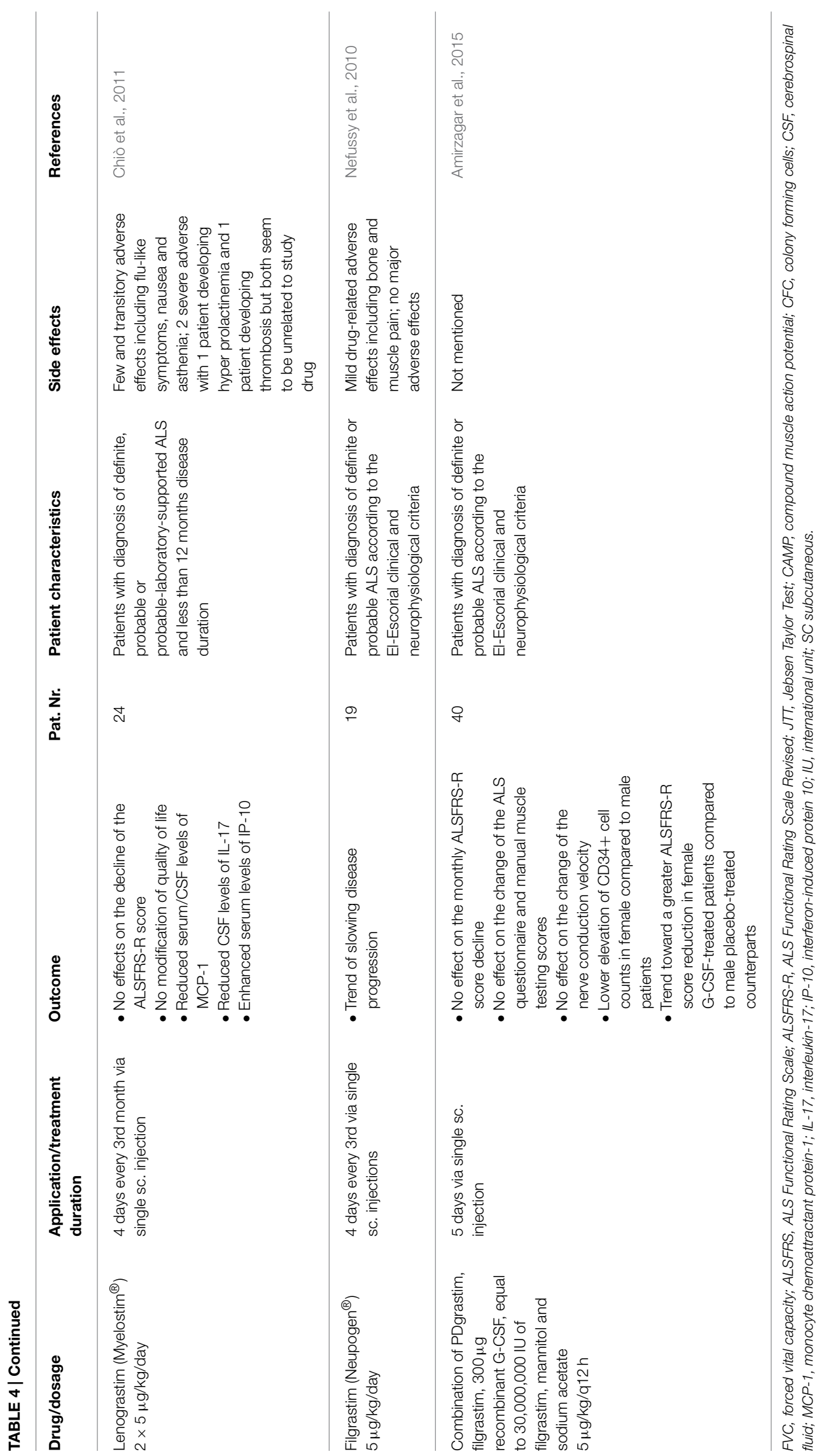


and show promising hints for efficacy, but larger randomized controlled studies are needed to get definite answers. Imaging (Duning et al., 2011) and potentially other biomarkers may help in clinical development in ALS. Several questions for clinical

\section{References}

Amirzagar, N., Nafissi, S., Tafakhori, A., Modabbernia, A., Amirzargar, A., Ghaffarpour, M., et al. (2015). Granulocyte colony-stimulating factor for amyotrophic lateral sclerosis: a randomized, double-blind, placebocontrolled study of Iranian patients. J. Clin. Neurol. 11, 164-171. doi: 10.3988/jcn.2015.11.2.164

Buschmann, I. R., Busch, H. J., Mies, G., and Hossmann, K. A. (2003). Therapeutic induction of arteriogenesis in hypoperfused rat brain via granulocyte-macrophage colony-stimulating factor. Circulation 108, 610-615. doi: 10.1161/01.CIR.0000074209.17561.99

Buschmann, I. R., Hoefer, I. E., van Royen, N., Katzer, E., Braun-Dulleaus, R., Heil, M., et al. (2001). GM-CSF: a strong arteriogenic factor acting by amplification of monocyte function. Atherosclerosis 159, 343-356. doi: 10.1016/S0021-9150(01)00637-2

Buschmann, I., and Schaper, W. (1999). Arteriogenesis versus angiogenesis: two mechanisms of vessel growth. News Physiol. Sci. 14, 121-125.

Buschmann, I., and Schaper, W. (2000). The pathophysiology of the collateral circulation (arteriogenesis). J. Pathol. 190, 338-342. doi: 10.1002/(SICI)10969896(200002)190:3<338::AID-PATH594>3.0.CO;2-7

Bussolino, F., Ziche, M., Wang, J. M., Alessi, D., Morbidelli, L., Cremona, O., et al. (1991). In vitro and in vivo activation of endothelial cells by colony-stimulating factors. J. Clin. Invest. 87, 986-995. doi: 10.1172/JCI1 15107

Cashman, N., Tan, L. Y., Krieger, C., Mädler, B., Mackay, A., Mackenzie, I., et al. (2008). Pilot study of granulocyte colony stimulating factor (G-CSF)-mobilized peripheral blood stem cells in amyotrophic lateral sclerosis (ALS). Muscle Nerve 37, 620-625. doi: 10.1002/mus.20951

Chi, L., Chun, L., and Rugao, L. (2006a). Increasing de novo neurogenesis for the therapy of motor neuron degeneration in ALS-like mice. Acta Pharmacol. Sin. 27, 430-430.

Chi, L., Gan, L., Luo, C., Lien, L., and Liu, R. (2007). Temporal response of neural progenitor cells to disease onset and progression in amyotrophic lateral sclerosis-like transgenic mice. Stem Cells Dev. 16, 579-588. doi: 10.1089/scd.2006.0120

Chi, L., Ke, Y., Luo, C., Li, B., Gozal, D., Kalyanaraman, B., et al. (2006b). Motor neuron degeneration promotes neural progenitor cell proliferation, migration, and neurogenesis in the spinal cords of amyotrophic lateral sclerosis mice. Stem Cells 24, 34-43. doi: 10.1634/stemcells.2005-0076

Chiò, A., Mora, G., La Bella, V., Caponnetto, C., Mancardi, G., Sabatelli, M., et al. (2011). Repeated courses of granulocyte colony-stimulating factor in amyotrophic lateral sclerosis: clinical and biological results from a prospective multicenter study. Muscle Nerve 43, 189-195. doi: 10.1002/mus.21851

Chung, J., Kim, M. H., Yoon, Y. J., Kim, K. H., Park, S. R., and Choi, B. H. (2014). Effects of granulocyte colony-stimulating factor and granulocytemacrophage colony-stimulating factor on glial scar formation after spinal cord injury in rats. J. Neurosurg. Spine 21, 966-973. doi: 10.3171/2014.8.SPINE1 31090

Crabtree, B., Thiyagarajan, N., Prior, S. H., Wilson, P., Iyer, S., Ferns, T., et al. (2007). Characterization of human angiogenin variants implicated in amyotrophic lateral sclerosis. Biochemistry 46, 11810-11818. doi: $10.1021 /$ bi701333h

Deindl, E., Zaruba, M. M., Brunner, S., Huber, B., Mehl, U., Assmann, G., et al. (2006). G-CSF administration after myocardial infarction in mice attenuates late ischemic cardiomyopathy by enhanced arteriogenesis. FASEB J. 20, 956-958. doi: 10.1096/fj.05-4763fje

Dela Peña, I. C., Yoo, A., Tajiri, N., Acosta, S. A., Ji, X., Kaneko, Y., et al. (2015). Granulocyte colony-stimulating factor attenuates delayed tPAinduced hemorrhagic transformation in ischemic stroke rats by enhancing development remain open, in particular feasibility and safety of a potentially yearlong treatment. Very recent and promising data support this (Grassinger et al., 2014; Khomenko et al., 2015).

angiogenesis and vasculogenesis. J. Cereb. Blood Flow Metab. 35, 338-346. doi: $10.1038 /$ jcbfm. 2014.208

Derakhshanrad, N., Saberi, H., Yekaninejad, M. S., Eskandari, G., Mardani, A., Rahdari, F., et al. (2013). Safety of granulocyte colony-stimulating factor (GCSF) administration for postrehabilitated motor complete spinal cord injury patients: an open-label, phase I study. Cell Transplant. 22(Suppl. 1), S139-S146. doi: 10.3727/096368913X672109

Déry, N., Pilgrim, M., Gibala, M., Gillen, J., Wojtowicz, J. M., Macqueen, G., et al. (2013). Adult hippocampal neurogenesis reduces memory interference in humans: opposing effects of aerobic exercise and depression. Front. Neurosci. 7:66. doi: 10.3389/fnins.2013.00066

Diederich, K., Schäbitz, W. R., and Minnerup, J. (2012). Seeing old friends from a different angle: novel properties of hematopoietic growth factors in the healthy and diseased brain. Hippocampus 22, 1051-1057. doi: 10.1002/hipo.20904

Diederich, K., Sevimli, S., Dörr, H., Kösters, E., Hoppen, M., Lewejohann, L., et al. (2009). The role of granulocyte-colony stimulating factor (G-CSF) in the healthy brain: a characterization of G-CSF-deficient mice. J. Neurosci. 29, 11572-11581. doi: 10.1523/JNEUROSCI.0453-09.2009

Dittgen, T., Pitzer, C., Plaas, C., Kirsch, F., Vogt, G., Laage, R., et al. (2012). Granulocyte-colony stimulating factor (G-CSF) improves motor recovery in the rat impactor model for spinal cord injury. PLoS ONE 7:e29880. doi: 10.1371/journal.pone.0029880

Duelsner, A., Gatzke, N., Glaser, J., Hillmeister, P., Li, M., Lee, E. J., et al. (2012). Granulocyte colony-stimulating factor improves cerebrovascular reserve capacity by enhancing collateral growth in the circle of Willis. Cerebrovasc. Dis. 33, 419-429. doi: 10.1159/000335869

Duning, T., Schiffbauer, H., Warnecke, T., Mohammadi, S., Floel, A., Kolpatzik, K., et al. (2011). G-CSF prevents the progression of structural disintegration of white matter tracts in amyotrophic lateral sclerosis: a pilot trial. PLoS ONE 6:e17770. doi: 10.1371/journal.pone.0017770

Gao, X., and Xu, Z. (2008). Mechanisms of action of angiogenin. Acta Biochim. Biophys. Sin. (Shanghai) 40, 619-624. doi: 10.1111/j.1745-7270.2008. 00442.x

Grassinger, J., Khomenko, A., Hart, C., Baldaranov, D., Johannesen, S. W., Mueller, G., et al. (2014). Safety and feasibility of long term administration of recombinant human granulocyte-colony stimulating factor in patients with amyotrophic lateral sclerosis. Cytokine 67, 21-28. doi: 10.1016/j.cyto.2014.02.003

Guo, Y., Zhang, H., Yang, J., Liu, S., Bing, L., Gao, J., et al. (2013). Granulocyte colony-stimulating factor improves alternative activation of microglia under microenvironment of spinal cord injury. Neuroscience 238, 1-10. doi: 10.1016/j.neuroscience.2013.01.047

Hanson, N. D., Owens, M. J., and Nemeroff, C. B. (2011). Depression, antidepressants, and neurogenesis: a critical reappraisal. Neuropsychopharmacology 36, 2589-2602. doi: 10.1038/npp.2011.220

Heil, M., Eitenmuller, I., Schmitz-Rixen, T., and Schaper, W. (2006). Arteriogenesis versus angiogenesis: similarities and differences. J. Cell. Mol. Med. 10, 45-55. doi: 10.1111/j.1582-4934.2006.tb00290.x

Henriques, A., Kastner, S., Chatzikonstantinou, E., Pitzer, C., Plaas, C., Kirsch, F., et al. (2014). Gene expression changes in spinal motoneurons of the SOD1(G93A) transgenic model for ALS after treatment with G-CSF. Front. Cell. Neurosci. 8:464. doi: 10.3389/fncel.2014.00464

Henriques, A., Pitzer, C., Dittgen, T., Klugmann, M., Dupuis, L., and Schneider, A. (2011). CNS-targeted viral delivery of G-CSF in an animal model for ALS: improved efficacy and preservation of the neuromuscular unit. Mol. Ther. 19, 284-292. doi: 10.1038/mt.2010.271

Henriques, A., Pitzer, C., and Schneider, A. (2010). Neurotrophic growth factors for the treatment of amyotrophic lateral sclerosis: where do we stand? Front. Neurosci. 4:32. doi: 10.3389/fnins.2010.00032 
Hibbert, B., Hayley, B., Beanlands, R. S., Le May, M., Davies, R., So, D., et al. (2014). Granulocyte colony-stimulating factor therapy for stem cell mobilization following anterior wall myocardial infarction: the CAPITAL STEM MI randomized trial. CMAJ 186, E427-E434. doi: 10.1503/cmaj.140133

Inada, T., Takahashi, H., Yamazaki, M., Okawa, A., Sakuma, T., Kato, K., et al. (2014). Multicenter prospective nonrandomized controlled clinical trial to prove neurotherapeutic effects of granulocyte colony-stimulating factor for acute spinal cord injury: analyses of follow-up cases after at least 1 year. Spine (Phila Pa 1976) 39, 213-219. doi: 10.1097/BRS.0000000000000121

Ingre, C., Roos, P. M., Piehl, F., Kamel, F., and Fang, F. (2015). Risk factors for amyotrophic lateral sclerosis. Clin. Epidemiol. 7, 181-193. doi: 10.2147/CLEP.S37505

Jin, K. L., Mao, X. O., and Greenberg, D. A. (2000a). Vascular endothelial growth factor: direct neuroprotective effect in in vitro ischemia. Proc. Natl. Acad. Sci. U.S.A. 97, 10242-10247. doi: 10.1073/pnas.97.18.10242

Jin, K. L., Mao, X. O., Nagayama, T., Goldsmith, P. C., and Greenberg, D. A. (2000b). Induction of vascular endothelial growth factor and hypoxia-inducible factor-1alpha by global ischemia in rat brain. Neuroscience 99, 577-585. doi: $10.1016 / \mathrm{S} 0306-4522(00) 00207-4$

Kadota, R., Koda, M., Kawabe, J., Hashimoto, M., Nishio, Y., Mannoji, C., et al. (2012). Granulocyte colony-stimulating factor (G-CSF) protects oligodendrocyte and promotes hindlimb functional recovery after spinal cord injury in rats. PLoS ONE 7:e50391. doi: 10.1371/journal.pone. 0050391

Kawabe, J., Koda, M., Hashimoto, M., Fujiyoshi, T., Furuya, T., Endo, T., et al. (2011). Neuroprotective effects of granulocyte colony-stimulating factor and relationship to promotion of angiogenesis after spinal cord injury in rats: laboratory investigation. J. Neurosurg. Spine 15, 414-421. doi: 10.3171/2011.5.SPINE10421

Khomenko, A., Baldaranov, D., Johannesen, S., Kobor, I., Blume, J., Bruun, T.-H., et al. (2015). Safety and feasibility of G-CSF compassionate use in ALS patients (P6.009). Neurology 84.

Kirsch, F., Krüger, C., and Schneider, A. (2008). The receptor for granulocytecolony stimulating factor (G-CSF) is expressed in radial glia during development of the nervous system. BMC Dev. Biol. 8:32. doi: 10.1186/1471213X-8-32

Koda, M., Nishio, Y., Kamada, T., Someya, Y., Okawa, A., Mori, C., et al. (2007). Granulocyte colony-stimulating factor (G-CSF) mobilizes bone marrowderived cells into injured spinal cord and promotes functional recovery after compression-induced spinal cord injury in mice. Brain Res. 1149, 223-231. doi: 10.1016/j.brainres.2007.02.058

Kuhlmann, M. T., Kirchhof, P., Klocke, R., Hasib, L., Stypmann, J., Fabritz, L., et al. (2006). G-CSF/SCF reduces inducible arrhythmias in the infarcted heart potentially via increased connexin 43 expression and arteriogenesis. J. Exp. Med. 203, 87-97. doi: 10.1084/jem.20051151

Lambrechts, D., Storkebaum, E., Morimoto, M., Del-Favero, J., Desmet, F., Marklund, S. L., et al. (2003). VEGF is a modifier of amyotrophic lateral sclerosis in mice and humans and protects motoneurons against ischemic death. Nat. Genet. 34, 383-394. doi: 10.1038/ng1211

Lee, S. T., Chu, K., Jung, K. H., Ko, S. Y., Kim, E. H., Sinn, D. I., et al. (2005). Granulocyte colony-stimulating factor enhances angiogenesis after focal cerebral ischemia. Brain Res. 1058, 120-128. doi: 10.1016/j.brainres.2005.07.076

Martinez, H. R., Gonzalez-Garza, M. T., Moreno-Cuevas, J. E., Caro, E., GutierrezJimenez, E., and Segura, J. J. (2009). Stem-cell transplantation into the frontal motor cortex in amyotrophic lateral sclerosis patients. Cytotherapy 11, 26-34. doi: 10.1080/14653240802644651

Martínez, H. R., Molina-Lopez, J. F., González-Garza, M. T., Moreno-Cuevas, J. E., Caro-Osorio, E., Gil-Valadez, A., et al. (2012). Stem cell transplantation in amyotrophic lateral sclerosis patients: methodological approach, safety, and feasibility. Cell Transplant. 21, 1899-1907. doi: 10.3727/096368911X5 82769

Miller, R. G., Mitchell, J. D., and Moore, D. H. (2012). Riluzole for amyotrophic lateral sclerosis (ALS)/motor neuron disease (MND). Cochrane Database Syst. Rev. 3:CD001447. doi: 10.1002/14651858.CD001447.pub3

Naumenko, N., Pollari, E., Kurronen, A., Giniatullina, R., Shakirzyanova, A., Magga, J., et al. (2011). Gender-specific mechanism of synaptic impairment and its prevention by GCSF in a mouse model of ALS. Front. Cell. Neurosci. 5:26. doi: $10.3389 /$ fncel.2011.00026
Nefussy, B., Artamonov, I., Deutsch, V., Naparstek, E., Nagler, A., and Drory, V. E. (2010). Recombinant human granulocyte-colony stimulating factor administration for treating amyotrophic lateral sclerosis: a pilot study. Amyotroph. Lateral Scler. 11, 187-193. doi: 10.3109/17482960902933809

Nicola, N. A., Metcalf, D., Matsumoto, M., and Johnson, G. R. (1983). Purification of a factor inducing differentiation in murine myelomonocytic leukemia cells. Identification as granulocyte colony-stimulating factor. J. Biol. Chem. 258, 9017-9023.

Nishio, Y., Koda, M., Kamada, T., Someya, Y., Kadota, R., Mannoji, C., et al. (2007). Granulocyte colony-stimulating factor attenuates neuronal death and promotes functional recovery after spinal cord injury in mice. J. Neuropathol. Exp. Neurol. 66, 724-731. doi: $10.1097 /$ nen.0b013e3181257176

Ohki, Y., Heissig, B., Sato, Y., Akiyama, H., Zhu, Z., Hicklin, D. J., et al. (2005). Granulocyte colony-stimulating factor promotes neovascularization by releasing vascular endothelial growth factor from neutrophils. FASEB J. 19, 2005-2007. doi: 10.1096/fj.04-3496fje

Oosthuyse, B., Moons, L., Storkebaum, E., Beck, H., Nuyens, D., Brusselmans, K., et al. (2001). Deletion of the hypoxia-response element in the vascular endothelial growth factor promoter causes motor neuron degeneration. Nat. Genet. 28, 131-138. doi: 10.1038/88842

Osada, T., Watanabe, M., Hasuo, A., Imai, M., Suyama, K., Sakai, D., et al. (2010). Efficacy of the coadministration of granulocyte colony-stimulating factor and stem cell factor in the activation of intrinsic cells after spinal cord injury in mice. J. Neurosurg. Spine 13, 516-523. doi: 10.3171/2010.4.SPINE09973

Oudega, M. (2012). Molecular and cellular mechanisms underlying the role of blood vessels in spinal cord injury and repair. Cell Tissue Res. 349, 269-288. doi: 10.1007/s00441-012-1440-6

Pan, H. C., Cheng, F. C., Lai, S. Z., Yang, D. Y., Wang, Y. C., and Lee, M. S. (2008). Enhanced regeneration in spinal cord injury by concomitant treatment with granulocyte colony-stimulating factor and neuronal stem cells. J. Clin. Neurosci. 15, 656-664. doi: 10.1016/j.jocn.2007.03.020

Pitzer, C., Klussmann, S., Kruger, C., Letellier, E., Plaas, C., Dittgen, T., et al. (2010). The hematopoietic factor granulocyte-colony stimulating factor improves outcome in experimental spinal cord injury. J. Neurochem. 113, 930-942. doi: 10.1111/j.1471-4159.2010.06659.x

Pitzer, C., Krüger, C., Plaas, C., Kirsch, F., Dittgen, T., Muller, R., et al. (2008). Granulocyte-colony stimulating factor improves outcome in a mouse model of amyotrophic lateral sclerosis. Brain 131, 3335-3347. doi: 10.1093/brain/awn243

Pollari, E., Savchenko, E., Jaronen, M., Kanninen, K., Malm, T., Wojciechowski, S., et al. (2011). Granulocyte colony stimulating factor attenuates inflammation in a mouse model of amyotrophic lateral sclerosis. J. Neuroinflammation 8:74. doi: $10.1186 / 1742-2094-8-74$

Pronto-Laborinho, A. C., Pinto, S., and de Carvalho, M. (2014). Roles of vascular endothelial growth factor in amyotrophic lateral sclerosis. Biomed Res. Int. 2014:947513. doi: 10.1155/2014/947513

Sabelström, H., Stenudd, M., and Frisen, J. (2014). Neural stem cells in the adult spinal cord. Exp. Neurol. 260, 44-49. doi: 10.1016/j.expneurol.2013.01.026

Saberi, H., Derakhshanrad, N., and Yekaninejad, M. S. (2014). Comparison of neurological and functional outcomes after administration of granulocytecolony-stimulating factor in motor-complete versus motor-incomplete postrehabilitated, chronic spinal cord injuries: a phase I/II study. Cell Transplant. 23(Suppl. 1), S19-S23. doi: 10.3727/096368914X684943

Sakuma, T., Yamazaki, M., Okawa, A., Takahashi, H., Kato, K., Hashimoto, M., et al. (2012). Neuroprotective therapy using granulocyte colony-stimulating factor for patients with worsening symptoms of compression myelopathy, Part 1: a phase I and IIa clinical trial. Eur. Spine J. 21, 482-489. doi: 10.1007/s00586011-2020-2

Sanli, A. M., Serbes, G., Caliskan, M., Kaptanoglu, E., Sargon, M. F., Kilinc, K., et al. (2010). Effect of granulocyte-colony stimulating factor on spinal cord tissue after experimental contusion injury. J. Clin. Neurosci. 17, 1548-1552. doi: 10.1016/j.jocn.2010.03.043

Santarelli, L., Saxe, M., Gross, C., Surget, A., Battaglia, F., Dulawa, S., et al. (2003). Requirement of hippocampal neurogenesis for the behavioral effects of antidepressants. Science 301, 805-809. doi: 10.1126/science.10 83328

Schmidt, A. K., Reich, A., Falkenburger, B., Schulz, J. B., Brandenburg, L. O., Ribes, S., et al. (2015). Adjuvant granulocyte colony-stimulating factor therapy results in improved spatial learning and stimulates hippocampal neurogenesis in a 
mouse model of pneumococcal meningitis. J. Neuropathol. Exp. Neurol. 74, 85-94. doi: 10.1097/NEN.0000000000000152

Schneeloch, E., Mies, G., Busch, H. J., Buschmann, I. R., and Hossmann, K. A. (2004). Granulocyte-macrophage colony-stimulating factor-induced arteriogenesis reduces energy failure in hemodynamic stroke. Proc. Natl. Acad. Sci. U.S.A. 101, 12730-12735. doi: 10.1073/pnas.0404880101

Schneider, A., Kruger, C., Steigleder, T., Weber, D., Pitzer, C., Laage, R., et al. (2005a). The hematopoietic factor G-CSF is a neuronal ligand that counteracts programmed cell death and drives neurogenesis. J. Clin. Invest. 115, 2083-2098. doi: 10.1172/JCI23559

Schneider, A., Kuhn, H. G., and Schäbitz, W. R. (2005b). A role for G-CSF (granulocyte-colony stimulating factor) in the central nervous system. Cell Cycle 4, 1753-1757. doi: 10.4161/cc.4.12.2213

Shihabuddin, L. S., Horner, P. J., Ray, J., and Gage, F. H. (2000). Adult spinal cord stem cells generate neurons after transplantation in the adult dentate gyrus. J. Neurosci. 20, 8727-8735.

Silverman, W. F., Krum, J. M., Mani, N., and Rosenstein, J. M. (1999). Vascular, glial and neuronal effects of vascular endothelial growth factor in mesencephalic explant cultures. Neuroscience 90, 1529-1541.

Storkebaum, E., and Carmeliet, P. (2004). VEGF: a critical player in neurodegeneration. J. Clin. Invest. 113, 14-18. doi: 10.1172/JCI20682

Storkebaum, E., Lambrechts, D., and Carmeliet, P. (2004). VEGF: once regarded as a specific angiogenic factor, now implicated in neuroprotection. Bioessays 26, 943-954. doi: 10.1002/bies.20092

Sugiyama, Y., Yagita, Y., Oyama, N., Terasaki, Y., Omura-Matsuoka, E., Sasaki, T., et al. (2011). Granulocyte colony-stimulating factor enhances arteriogenesis and ameliorates cerebral damage in a mouse model of ischemic stroke. Stroke 42, 770-775. doi: 10.1161/STROKEAHA.110.597799

Takahashi, H., Yamazaki, M., Okawa, A., Sakuma, T., Kato, K., Hashimoto, M., et al. (2012). Neuroprotective therapy using granulocyte colony-stimulating factor for acute spinal cord injury: a phase I/IIa clinical trial. Eur. Spine J. 21, 2580-2587. doi: 10.1007/s00586-012-2213-3

Urdzíková, L., Jendelová, P., Glogarová, K., Burian, M., Hájek, M., and Syková, E. (2006). Transplantation of bone marrow stem cells as well as mobilization by granulocyte-colony stimulating factor promotes recovery after spinal cord injury in rats. J. Neurotrauma 23, 1379-1391. doi: 10.1089/neu.2006.23.1379

van Praag, H., Christie, B. R., Sejnowski, T. J., and Gage, F. H. (1999). Running enhances neurogenesis, learning, and long-term potentiation in mice. Proc. Natl. Acad. Sci. U.S.A. 96, 13427-13431.

Van Royen, N., Piek, J. J., Schaper, W., Bode, C., and Buschmann, I. (2001). Arteriogenesis: mechanisms and modulation of collateral artery development. J. Nucl. Cardiol. 8, 687-693. doi: 10.1067/mnc.2001. 118924

Winner, B., and Winkler, J. (2015). Adult neurogenesis in neurodegenerative diseases. Cold Spring Harb. Perspect. Biol. 7:a021287. doi: 10.1101/cshperspect.a021287

Wu, D., Yu, W., Kishikawa, H., Folkerth, R. D., Iafrate, A. J., Shen, Y., et al. (2007). Angiogenin loss-of-function mutations in amyotrophic lateral sclerosis. Ann. Neurol. 62, 609-617. doi: 10.1002/ana.21221

Wyndaele, M., and Wyndaele, J. J. (2006). Incidence, prevalence and epidemiology of spinal cord injury: what learns a worldwide literature survey? Spinal Cord 44, 523-529. doi: 10.1038/sj.sc.3101893

Yamasaki, R., Tanaka, M., Fukunaga, M., Tateishi, T., Kikuchi, H., Motomura, K., et al. (2010). Restoration of microglial function by granulocyte-colony stimulating factor in ALS model mice. J. Neuroimmunol. 229, 51-62. doi: 10.1016/j.jneuroim.2010.07.002

Yau, S. Y., Lau, B. W., Tong, J. B., Wong, R., Ching, Y. P., Qiu, G., et al. (2011). Hippocampal neurogenesis and dendritic plasticity support running-improved spatial learning and depression-like behaviour in stressed rats. PLoS ONE 6:e24263. doi: 10.1371/journal.pone.0024263

Zhang, Y., Wang, L., Fu, Y., Song, H., Zhao, H., Deng, M., et al. (2009) Preliminary investigation of effect of granulocyte colony stimulating factor on amyotrophic lateral sclerosis. Amyotroph. Lateral Scler. 10, 430-431. doi $10.3109 / 17482960802588059$

Conflict of Interest Statement: The authors have read the journal's policy and have the following conflicts: Armin Schneider and Ulrich Bogdahn are inventors on patent applications claiming the use of G-CSF for spinal cord injury treatment. There are no other patents, products in development or marketed products to declare. This does not alter the authors' adherence to all the Frontiers policies on sharing data and materials. The other authors declare that the research was conducted in the absence of any commercial or financial relationships that could be construed as a potential conflict of interest.

Copyright (C) 2015 Wallner, Peters, Pitzer, Resch, Bogdahn and Schneider. This is an open-access article distributed under the terms of the Creative Commons Attribution License (CC BY). The use, distribution or reproduction in other forums is permitted, provided the original author(s) or licensor are credited and that the original publication in this journal is cited, in accordance with accepted academic practice. No use, distribution or reproduction is permitted which does not comply with these terms. 